\title{
PENGEMBANGAN LKPD MATERI HIMPUNAN KONTEKS PENCARIAN HARTA KARUN DI SUNGAI MUSI
}

\author{
Rika Firma Yenni ${ }^{1}$, Malalina*2, Dian Apriani $^{3}$ \\ FKIP Universitas Tamansiswa, Jalan Tamansiswa No. 261 Palembang ${ }^{1,2,3}$ \\ e-mail: malalina@unitaspalembang.ac.id
}

\begin{abstract}
ABSTRAK
Sumber belajar yang dapat dikembangkan untuk membantu peserta didik menjadi aktif dan memahami materi salah satunya adalah LKPD. LKPD adalah bahan ajar berupa lembaran didesain berisi latihan berisi langkah-langkah tugas yang harus diselesaikan peserta didik. Rumusan masalah dalam penelitian ini adalah bagaimana mengembangkan LKPD materi himpunan konteks pencarian harta karun di Sungai Musi yang valid dan praktis. Metode penelitian yang digunakan adalah pengembangan dengan dua tahap yaitu preliminary study dan formatif study. Penelitian ini hanya pada tahap self evaluation, expert review, one to one, dan small group dengan teknik pengumpulan data menggunakan walk through, dokumentasi, wawancara, dan angket. Penelitian ini menghasilkan produk LKPD materi himpunan konteks pencarian harta karun di Sungai Musi dengan kategori valid dan praktis.
\end{abstract}

\section{Kata kunci :}

Himpunan, LKPD, Konteks

\begin{abstract}
One of the learning resources that can be developed to help students become active and understand the material is LKPD. LKPD is a teaching material in the form of a sheet designed to contain exercises containing the steps of the task that must be completed by students. The formulation of the problem in this research is how to develop valid and practical LKPD for the context of finding treasures in the Musi River. The research method used is development with two stages, namely preliminary study and formative study. This research is only at the stage of self evaluation, expert review, one to one, and small group with data collection techniques using walk through, documentation, interviews, and questionnaires. This research produces LKPD products for the context of finding treasures in the Musi River with valid and practical categories.
\end{abstract}

Keywords :

Set, LKPD, Context

\section{PENDAHULUAN}

Investasi pendidikan merupakan hal yang perlu dilakukan dalam rangka pengembangan jangka panjang sumber daya manusia. Menurut Undang-undang nomor 20 Tahun 2003 tentang Sistem Pendidikan Nasional tujuan Pendidikan nasional adalah mengembangkan potensi peserta didik agar menjadi manusia yang beriman dan bertakwa kepada Tuhan Yang Maha Esa, berakhlah mulia, sehat, berilmu, cakap, kreatif, mandiri dan menjadi warga negara yang demokratis serta bertanggung jawab. Oleh karena itu, peningkatan sumber daya manusia dapat dilakukan melalui endidikan.
Namun dalam pelaksanaannya banyak permasalahan yang timbul. Menurut Zulkardi (2002) menyatakan inti dari permasalahan pendidikan matematika yang ada di Indonesia terlihat dari rendahnya prestasi siswa pada tingkat nasional ataupun internasional. Selain itu, guru menggunakan materi pembelajaran secara langsung dan bersifat abstark menyebabkan peserta didik menjadi pasif untuk bertanya (Aswarliansyah, 2020). Serta peserta didik hanya difokuskan untuk menyelesaikan soalsoal latihan (Fairuz et al., 2020). Sumber belajar yang dapat dikembangkan untuk membantu peserta didik menjadi aktif dan 


\section{$\pi$ (Phi)}

memahami materi salah satunya adalah LKPD.

Menurut Relia (2016) LKPD digunakan untuk membantu peserta didik menunjukkan pengetahuan, pemahaman dan kemampuan yang dimiliki. Sejalan dengan hal itu, Trianto (2012) menyatakan LKPD adalah bahan ajar cetak yang memiliki pertanyaan untuk dijawab dengan tujuan untuk membantu serta mengarahkan peserta didik dalam belajar. LKPD adalah lembaranlembaran berisi langkah-langkah atau yang harus diselesaikan oleh peserta didik (Majid, 2006; Prastowo, 2012). Menurut depdiknas (2008) LKPD minimal memuat judul, kompetensi dasar, informasi singkat, waktu penyelesaian, langkah kegiatan pembelajaran serta tugas yang wajib diselesaikan peserta didik.

Manfaat LKPD yaitu dapat dijadikan pedoman baik bagi pendidik maupun peserta didik dalam proses pembelajaran untuk memahami konsep serta melatih menemukan dan mengembangkan keterampilan proses (Umbaryati, 2016). Komponen LKPD adalah judul, petunjuk belajar, kompetensi yang akan dicapai, materi pokok, informasi pendukung, tugas dan langkah kerja dan penilaian (Depdiknas, 2008). Dengan demikian LKPD merupakan bahan sumber belajar berupa lembaran yang didesain berisi latihan atau tugas yang harus diselesaikan peserta didik.

Hasil Penelitian Khasanah (2018) Penggunaan LKPD pada materi Geometri Transformasi dengan menggunakan Motif Tapis Lampung dapat meningkatkan pemahaman peserta didik. Selain itu, Ricardo (2020) menyatakan LKPD berbasis konteks dapat digunakan untuk menyampaikan sebuah konsep pembelajaran dalam matematika. Hal yang sama dinyatakan oleh Susiloningsih and Karlina (2015) lembar kerja siswa berbasis kontekstual dapat digunakan untuk meningkatkan hasil belajar siswa.

Penelitian ini fokus pada pengembangan LKPD menggunakan konteks. Konteks adalah situasi yang dijadikan sebagai suatu permasalahan yang dapat dijadikan solusi terhadap permasalahan tersebut (HeuvelPanhuizen, 1996). Pembelajaran dengan memanfaatkan konteks menunjang guru untuk mengkaitkan antara materi dengan situasi nyata dan dapat menciptakan hubungan antara pengetahuan yang dimiliki peserta didik dalam aplikasi aktivitas kehidupan (Afriani, 2018). Trend ataupun arah pendekatan pembelajaran matematika di Sekolah saat ini adalah pemakaian konteks (Zulkardi \& Ilma, 2006)

Simanulang (2014) konteks laskar pelangi dapat dikembangkan menjadi bahan ajar materi himpunan yang valid, praktis dan mempunyai efek potensial. Selain itu, Rahmadona (2021) Penggunaan konteks buah jambu biji dapat dikembangkan dalam bentuk LKPD yang digunakan untuk pemahaman konsep materi bola. Dengan demikian konteks yang ada di lingkungan peserta didik dapat digunakan dalam pentuk pembelajaran matematika.

Konteks yang akan digunakan dalam penelitian ini merupakan aktivitas yang terdapat di Sungai Musi. Menurut Malalina et al (2020) terdapat materi matematika dalam kegiatan penangkapan ikan di sungai Musi yaitu materi koordinat kartesius, materi volume, himpunan, aritmatika sosial, kecepatan, jarak dan geometri. Selain itu, Malalina et al (2020) Aktivitas pencarian harta karun mengandung konsep matematika pada pembelajaran matematika tingkat SMP Kelas VII yaitu materi operasi hitung, aritmatika sosial dan himpunan.

Berdasarkan uraian di atas, maka peneliti merumuskan masalah dalam penelitian ini adalah bagaimana mengembangkan LKPD materi himpunan dengan konteks pencarian harta karun di Sungai Musi yang valid dan praktis.

\section{METODE PENELITIAN}

Pengembangan atau development research metode yang digunakan untuk penelitian ini yang dari dua tahap yaitu preliminary study 


\section{$\pi$ (Phi)}

dan formatif study. Preliminary study merupakan tahap persiapan sedangkan formatif study merupakan tahap evaluasi dan revisi. Gambar 1 dibawah ini merupakan langkah-langkah dalam mengembangkan LKPD materi himpunan konteks pencarian harta karun di Sungai Musi.

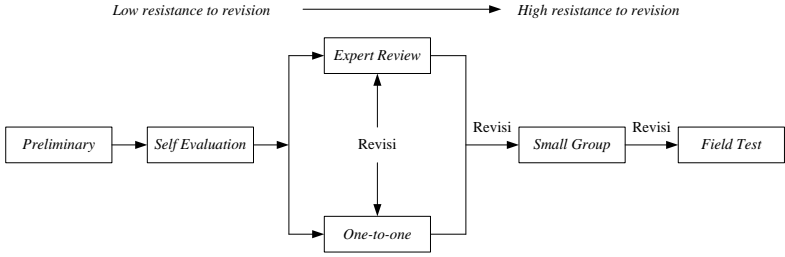

Gambar 1. Alur desain formative evaluation Tessmer (Zulkardi, 2006)

Penelitian ini hanya pada tahap self evaluation, expert review, one to one evaluation dan small group. Sedangkah tahapan field Test tidak dilakukan dikarenakan kondisi pembelajaran tatap muka yang tidak memungkinkan.

Walk through, dokumentasi, wawancara, dan angket adalah teknik pengumpulan data yang digunakan dalam penelitian ini. Sedangkan waktu pelaksanaan penelitian dari bulan Maret - Juli 2021

\section{HASIL DAN PEMBAHASAN}

Proses pengembangan LKPD konteks pencarian harta karun di Sungai Musi materi himpunan yang dikembangkan telah melalui tahapan tahap tahap preliminary dan formative study. Pada tahap preliminary peneliti mengidentifikasi kurikulum yang ada di Buku Paket Matematika dan dan sumber belajar yang bisa digunakan, materi serta mendesain RPP dan LKPD serta tes hasil belajar. Sedangkan tahap formative study meliputi self evaluation, expert review, one to one dan small group.

Pada setiap tahapan terdapat revisi yang digunakan agar LKPD konteks pencarian harta karun di Sungai Musi mendapatkan katagori valid dan praktis.

\section{Self Evaluation}

Pada Tahap ini peneliti menilai sendiri terhadap pendesainan LKPD materi himpunan dengan menggunakan Konteks Pencarian Harta Karun di Sungai Musi yang dikembangkan berdasarkan segi konten, konstruk dan bahasa. Hasil LKPD pada tahap self evaluation dinamakan prototype pertama. Hasil dari desain LKPD materi himpunan konteks pencarian harta karun di Sungai Musi merupakan prototype pertama yang disajikan pada gambar 2 .
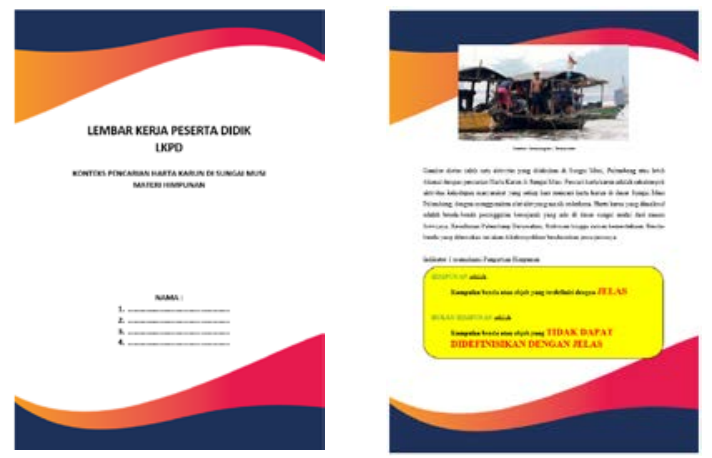

Gambar 2. LKPD Prototype Awal

Gambar 2 merupakan prototype awal yaitu bagian cover materi himpunan. Pada tahap self evaluation peneliti melakukan sendiri evaluasi terhadap LKPD yang telah didesain. Tahap ini digunakan untuk melihat secara jelas hasil LKPD yang telah didesain peneliti. Selanjutnya prototype pertama akan divalidasi pada tahap expert review.

\section{Expert Review}

Expert review merupakan validator yang memvalidasi LKPD materi himpunan konteks pencarian harta karun di Sungai Musi yang telah dibuat oleh peneliti dengan tujuan untuk mengetahui kualitas kevalidan dari LKPD yang dikembangkan.

Validator yang digunakan untuk menilai LKPD Konteks pencarian harta karun di Sungai Musi terdiri dari tiga validator yang tediri dari satu orang dosen Pendidikan matematika dan dua orang guru matematika. Validasi ini dilakukan melalui whatsapp dan tatap muka. Berdasarkan 3 Validator yang menilai LKPD materi Himpunan Konteks

Rika Firma Yenni, Malalina, Dian Apriani

Pengembangan LKPD materi Himpunan Konteks Pencarian Harta Karun di Sungai Musi 


\section{$\pi$ (Phi)}

Pencarian Harta Karun di Sungai Musi menyatakan baik berdasarkan konten, konstruk dan bahasa. Adapun hasil saran dan komentar ketiga validator diuraikan pada tabel 1 berikut.

Tabel 1 Saran dan Komentar terhadap LKPD

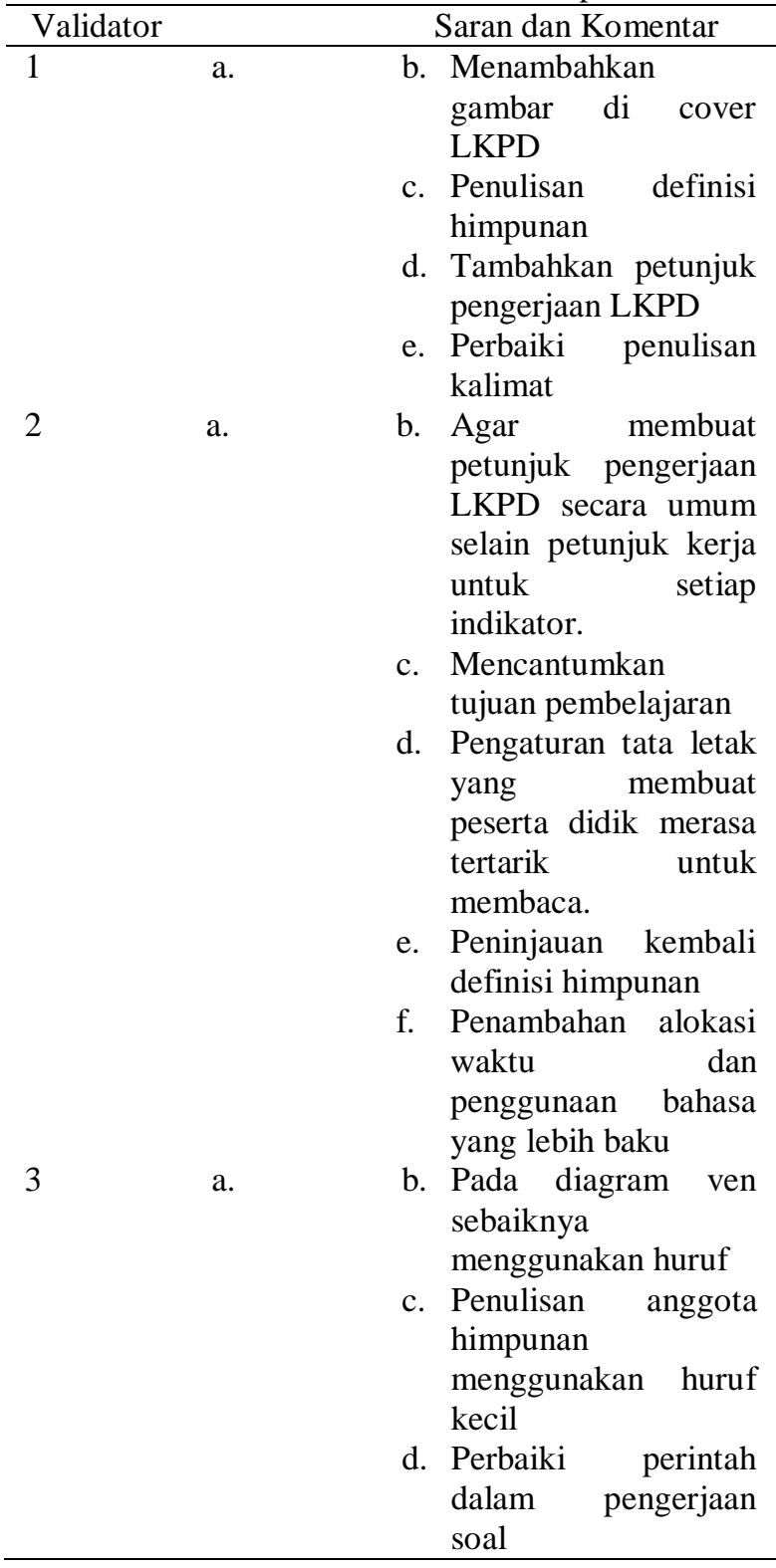

Tabel 1 diatas merupakan saran dari ketiga validator untuk perbaikan LKPD. Hasil dari expert review akan digunakan sebagai dasar dalam perbaikan untuk membuat prototype kedua.

Selain saran yang diberikan, validator juga mengisi lembar validasi yang digunakan untuk mengetahui kategori dari LKPD yang telah dibuat oleh peneliti. Adapun kriteria kevalidan berdasarkan validasi para pakar disajikan paada tabel 2 berikut :

Tabel 2 Rekapitulasi Validasi dari pakar

\begin{tabular}{cccc}
\hline Validator & Konstruk & $\begin{array}{c}\text { Jumlah skor } \\
\text { Konten }\end{array}$ & Bahasa \\
\hline 1 & 14 & 19 & 20 \\
2 & 23 & 29 & 22 \\
3 & 19 & 22 & 14 \\
\hline $\begin{array}{c}\text { Persentase } \\
\text { Skor }\end{array}$ & 75 & 78 & 77 \\
\hline
\end{tabular}

Tabel 2 merupakan hasil dari penilaian validator terhadap LKPD materi himpunan konteks pencarian harta karun di Sungai Musi. Berdasarkan kriteria kevalidan Arikunto (2006) maka LKPD yang telah didesain oleh peneliti masuk dalam kategori valid.

\section{One to one}

One to one dilakukan kepada peserta didik yang memiliki kemampuan rendah, sedang dan tinggi. Pelaksanaan one to one dilakukan secara terpisah sebanyak 3 peserta didik. Uji coba yang dilakukan satu persatu kepada peserta didik. Setelah peserta didik menyelesaikan LKPD kemudian peserta didik diberikan angket terkait penggunaan LKPD yang telah dibuat. Hasil rekapitulasi kepraktisan LKPD pada one to one adalah 84\%. Menurut Arikunto (2017), berdasarkan kriteria kepraktisan LKPD yang diujicobakan pada 3 peserta didik masuk dalam kategori praktis.

Selain itu juga peneliti melakukan wawancara tidak terstruktur pada tahap one to one. Ketiga peserta didik menyatakan bahwa sangat senang belajar menggunakan konteks yang ada dilingkungan sekitar.

\section{Small Group}

Small Group diujicobakan kepada 6 peserta didik yang mempunyai kemampuan rendah, sedang dan tinggi. Pelaksanaan 


\section{$\pi$ (Phi)}

small group dilakukan melalui whatsapp group antara peserta didik, guru dan peneliti.

Diakhir ujicoba pada small group peserta diberikan angket yang diisi melalui google form. Hasil angket pada small group menyatakan bahwa LKPD materi himpunan dengan konteks pencarian harta karun di Sungai Musi yaitu sebesar 82,33\%. Menurut Arikunto (2017), berdasarkan hasil ujicoba LKPD pada small group yang diujicobakan pada 6 peserta didik masuk dalam kategori praktis.

Berdasarkan uraian diatas dapat disimpulkan bahwa LKPD materi himpunan dengan konteks pencarian harta karun di Sungai Musi memiliki kualitas valid dan praktis. Hal ini sesuai dengan penelitian Nasrullah (2020) Penggunaan konteks dalam pembelajaran matematika dapat mendukung dan menggiatkan inovasi pembelajaran. Hal ini dipertegas oleh Zulkardi dan Ilma (2006) bahwa penggunaan konteks dalam pembelajaran membuat peserta didik menyenangi dan mengerti matematika.

\section{SIMPULAN}

Penelitian yang telah dilakukan menghasilkan suatu produk LKPD himpunan menggunakan konteks pencarian harta karun di Sungai Musi. Proses pengembangan LKPD ini terdiri dari tahap analisis, desain, evaluasi dan revisi. Berdasarkan hasil penelitian maka diperoleh kesimpulan yaitu penelitian ini telah menghasilkan produk LKPD materi himpunan konteks pencarian harta karun di Sungai Musi dengan kategori valid dan praktis.

\section{UCAPAN TERIMA KASIH}

Peneliti mengucapkan terima kasih kepada Lembaga Penelitian Universitas Tamansiswa Palembang yang telah memberikan hibah internal dengan Surat Perjanjian Kontrak Penelitian No. 011/UTS/LP/B.06/Plg/2021.

\section{DAFTAR PUSTAKA}

Afriani, A. (2018). Pembelajaran
Kontekstual (Cotextual Teaching And Learning) dan Pemahaman Konsep Siswa. Jurnal Muta'aliyah, 1(1).

Arikunto, S. (2006). Dasar-Dasar Evaluasi Pendidikan. Bumi Aksara.

Arikunto, S. (2017). Penelitian Tindakan Kelas.

Aswarliansyah. (2020). Pengembangan Lembar Kerja Siswa Berbasis Kontekstual Untuk Meningkatkan Hasil Belajar Matematika di Sekolah Dasar. Jurnal Basicedu, 4(4), 1134-1141.

Depdiknas. (2008). Pengembangan Bahan Ajar. Direktorat Pembinaan Sekolah Menengah Atas Direktorat Jenderal Manajemen Pendidikan Dasar dan Menengah Departemen Pendidikan Nasional.

Fairuz, F. R., Fajriah, N., \& Danaryanti, A. (2020). Pengembangan Lkpd Materi Pola Bilangan Berbasis Etnomatematika Sasirangan di Kelas VIII Sekolah Menengah Pertama. EDUMAT: Jurnal Pendidikan Matematika, 8(1). https://doi.org/10.20527/edumat.v8i1.8 343

Heuvel-Panhuizen, van den. (1996). Assessment and Realistic Mathematics Education. Freudenthal Institute.

Khasanah, B. A., \& Fadila, A. (2018). Pengembangan LKPD Geometri Transformasi dengan Motif Tapis Lampung. JURNAL E-DuMath, 4(2), 59.

https://doi.org/10.26638/je.734.2064

Majid, A. (2006). Perencanaan Pembelajaran: Mengembangkan Standar Kompetensi Guru. PT Remaja Rosdakarya.

Malalina, M, Putri, R. I. I., Zulkardi, Z., \& Hartono, Y. (2020). Ethnomathematics of fish catching exploration in Musi River. Journal of Physics: Conference Series, 1663, 012007. https://doi.org/10.1088/17426596/1663/1/012007

Malalina, Malalina, Putri, R. I. I., Zulkardi,

Rika Firma Yenni, Malalina, Dian Apriani

Pengembangan LKPD materi Himpunan Konteks Pencarian Harta Karun di Sungai Musi 


\section{$\pi$ (Phi)}

Z., \& Hartono, Y. (2020). Ethnomatematics: Treasure Search Activity in the Musi River. NUMERICAL: Jurnal Matematika Dan Pendidikan Matematika, 31-40. https://doi.org/10.25217/numerical.v4i1 .870

Nasrullah, N., Sanusi, W., \& Abdy, M. (2020). MPM Berbasis Konteks dan Strategi Pembelajaran Matematika Realistik Bagi Guru Matematika Tingkat SMP. DEDIKASI, 22(2). https://doi.org/10.26858/dedikasi.v22i2. 16137

Prastowo, A. (2012). Panduan Kreatif Membuat Bahan Ajar Iniovatif. Diva Press.

Rahmadona, D., Putri, A. D., \& Ramury, F. (2021). Penggunaan Konteks Buah Jambu Biji dalam Pengembangan LKPD Berbasis Pendekatan PMRI pada Materi Bola untuk Peserta Didik Kelas IX SMP. MAJU: Jurnal Ilmiah Pendidikan Matematika, 8(1), 71-81.

Relia, L. (2016). Keterkaitan antara Lembar Kerja Peserta Didik (LKPD) Matematika dengan Model Pembelajaran Kreatif, Inovatif, dan Produktif (KIP). PRISMA, Prosiding Seminar Nasional Matematika, 97-103.

Richardo, R. (2020). Rino Richardo. Jurnal Pendidikan Matematika, 3(1), 86-98.

Simanulang, J. (2014). Pengembangan Bahan AJAR Materi Himpunan Konteks Laskar Pelangi dengan Pendekatan Pendidikan Matematika Realistik Indonesia (PMRI) Kelas VII Sekolah Menengah Pertama. Jurnal Pendidikan Matematika, 8(1), 43-54.

Susiloningsih, E., \& Karlina, R. (2015). Lembar Kerja Siswa Berbasis Kontekstual Dalam Pembelajaran Subtema "Aku Bangga Dengan Daerah Tempat Tinggalku.” Jurnal Inovasi Sekolah Dasar, 2(2), 100-106.

Trianto. (2012). Mendesain Model Pembelajaran Inovatif-Progresif: Konsep, Landasan, dan
Implementasinya Pada Kurikulum Tingkat Satuan Pendidikan. Kencana Prenada Media Group.

Umbaryati. (2016). Pentingnya LKPD pada Pendekatan Scientific Pembelajaran Matematika. PRISMA, Prosiding Seminar Nasional Matematika, 217225.

Zulkardi. (2002). Pendidikan Matematika di Indonesia: beberapa Permasalahan dan Upaya Penyelesaiannya.

Zulkardi. (2006). Formative Evaluation: What, Why, When, How. http://www.reocities.com/zulkardi/book s.html

Zulkardi, \& Ilma, R. (2006). Mendesain Sendiri Soal Kontekstual Matematika. Prosiding KNM13 Semarang. 